failures during commercial sex were also apparently common, it is possible that female prostitutes are as much at risk of infection from their clients as clients are at risk from prostitutes.

Female prostitutes and their male sexual partners together appear to link otherwise separate parts of large populations through a range of relationships. Further research on these sexual networks and the interconnections between different risk behaviours is needed for the assessment of potential transmission of HIV.

We thank participants for their patience and help with this research; Forum magazine for publicity; and Jonathan Weber and David Miller for helpful technical and editorial comments on a draft of this paper. This study was supported by North West Thames Regional Health Authority and the Jefferiss Research Trust.

1 Alexander P. Prostitutes are being scapegoated for heterosexual AIDS. In Delacoste F, Alexander P, eds. Sex work: writings by women in the sex industry. London: Virago Press, 1990:15-23.

\section{Risk behaviours among male clients of female prostitutes}

\author{
Marina A Barnard, Neil P McKeganey, \\ Alastair H Leyland
}

Public Health Research Unit, University of Glasgow, Glasgow G12 8RZ

Marina A Barnard, research fellow

Neil P McKeganey, senior research fellow

Alastair H Leyland,

statistician

Correspondence to:

Dr Barnard.

$B M 71993 ; 307: 361-2$ largely covert.
In contrast to research on prostitutes' risk behaviours related to infection with HIV, little work has been done on the sexual behaviours of prostitutes' clients. Such research is bedevilled with problems of recruitment and obtaining a representative sample, making use of conventional survey methods difficult. In this study we recruited 143 clients of prostitutes. Although the results cannot be seen as representative, they shed some light on aspects of sexual behaviour that are

\section{Subjects, methods, and results}

Clients were recruited in three settings and asked to complete a short structured questionnaire: 68 were recruited in two genitourinary clinics in Glasgow; 66 were interviewed by telephone after answering an advertisement we had placed in a national tabloid; and nine were cold contacted in Glasgow's red light area (the small number contacted in this way reflecting the difficulties associated with this form of recruitment). The results for the men recruited by the last two methods were combined to give a non-clinic group for statistical analysis.

The table shows some of the background characteristics of the clients. The men reported having paid for sexual services a median of seven times (range 1-2000) since 1980. Higher numbers of contacts were reported by the non-clinic group: $28(37 \%)$ of these men reported having had 21-50 contacts, significantly

Characteristics of male clients of prostitutes in Glasgow who were recruited from two genitourinary clinics (clinic group) or by advertisements or by direct contact in red light district (non-clinic group). Values are numbers (percentages) unless otherwise stated

\begin{tabular}{|c|c|c|c|}
\hline & $\begin{array}{l}\text { Clinic } \\
\text { group } \\
(n=68)\end{array}$ & $\begin{array}{l}\text { Non-clinic } \\
\text { group } \\
(n=75)\end{array}$ & $\begin{array}{c}\text { Total } \\
(n=143)\end{array}$ \\
\hline Mean (range) age (years) & $36 \cdot 8(21-60)$ & $35 \cdot 2(23-63)$ & $36 \cdot 0(21-63)$ \\
\hline Unemployed & $10(15)$ & $6(8)$ & $16(11)$ \\
\hline Married or cohabiting & $23(34)$ & $49(65)$ & $72(50)$ \\
\hline \multicolumn{4}{|l|}{ History of sexually transmitted } \\
\hline infection & $31(46)$ & $4(5)$ & $35(24)$ \\
\hline Tested for HIV & $31(46)$ & $12(16)$ & $43(30)$ \\
\hline
\end{tabular}

2 Plummer FA, Nagelkerke NJD, Moses S, Ndinya-Achola JO, Bwayo J, Ngugi E. The importance of core groups in the epidemiology and control of HIV infection. AIDS 1991;5(suppl 1):S169-76.

3 Wallace J, Mann J, Beatrice S. HIV exposure among clients of prostitutes. In: Organising Committee, ed. Proceedings of IV international conference on AIDS, fune 12-16, 1988, Stockholm. Stockholm: Organising Committee, AIDS, fune 12-16, 1988,
1988:273. (Abstract 4055.)

4 Chiasson NA, Stoneburner R, Lifson A, Hildebrandt D, Jaffe H. No association between HIV-1 seropositivity and prostitute contact in New York City. In: Organising Committee, ed. Proceedings of IV international conference on AIDS, fune 12-16, 1988, Stockholm. Stockholm: Organising Committee, 1988:273. (Abstract 4053.)

5 Ward H, Day S. Prostitution. In: Harris JRW, Forster S, eds. Recent advances in STD and AIDS - 4. Edinburgh: Churchill Livingstone, 1990:183-99.

6 McLeod E. Women working: prostitution now. London: Croom Helm, 1982.

7 Kinnell H. Prostitutes, their clients and risks of HIV infection in Birmingham. Occasional paper. Birmingham: Central Birmingham Health Authority, 1989.

8 Melbye M, Biggar RJ. Interactions between persons at risk for AIDS and the general population in Denmark. Am $\mathcal{f}$ Epidemiol 1992;135:593-602.

9 Ward H, Day S, Mezzone J, Dunlop L, Donegan C, Farrar S, et al. Prostitution and risk of HIV: female prostitutes in London. BMf 1993;307: Prostit.

10 Day S. Anthropological perspectives on sexually transmitted diseases. In: Job-Spira N, Spencer B, Moalti JP, Bouvet E, eds. Sante publique et maladies a transmission sexuelle. Paris: John Libbey Eurotext, 1990:88-97.

(Accepted 26 May 1993)

more than the clinic group, $28(41 \%)$ of whom reported having had 1-10 contacts.

The median time that had elapsed since the men's last contact with a prostitute was 60 days. Most of the men (103) reported having paid for vaginal intercourse during this contact; 89 paid for masturbation or other non-penetrative sex; 87 paid for oral sex; and 11 paid for anal intercourse. Clearly, some men engaged in more than one sexual activity. Condoms were not used by 17 men when they had last paid for vaginal intercourse and by 31 men when they last had oral sex, but all anal intercourse was reportedly protected. Condom failure was reported by $14 \%$ $(19 / 133)$ of those who had used a condom when they had last purchased sexual services. Having unprotected vaginal intercourse was most likely to be reported by men who contacted prostitutes working on the streets: $32 \%(10 / 31)$ of these men had not used a condom during their last contact. Most clients reported having had no previous sexual contact with the prostitutes from whom they purchased unprotected sex.

Most men (121) reported having private, noncommercial sexual contacts: 79 reported having one sexual partner, and 42 reported having two or more concurrent sexual partners (range 2-20), two of whom reported sexual contacts with other men. Most men (117) reported having had vaginal intercourse while 85 had had oral sex, 82 had had other non-penetrative sex, and 16 had had anal intercourse. A minority of these men reported always using condoms with their partners: $24 \%(27 / 114)$ of those having vaginal intercourse, $5 \%(4 / 80)$ of those having oral sex, and $33 \%$ $(5 / 15)$ of those having anal intercourse. No relation was found between condom use and number of private partners. Ten men reported at least one condom failing with a partner in the past year.

\title{
Comment
}

Condoms were used for most of the commercial sexual contacts reported in this study. In view of the low levels of infection with HIV among female prostitutes $^{1}$ it is probably unwise to overstate the case for heterosexual transmission of HIV through commercial sexual contacts. ${ }^{2}$ Some unprotected sex, however, was reported with prostitutes, mainly women with whom the men had not had previous sexual contact. This contrasts with two studies which found that men were least likely to use condoms with prostitutes of whom they were regular clients. ${ }^{34}$ In addition, condoms were not used with most private sexual partners. These factors suggest that more 
attention should be paid to the activities of male clients of prostitutes.

We thank Dr Ivan Tait and all the staff working at the genitourinary hospital clinics in Glasgow for their help and support over the past two years. This study was funded by the Medical Research Council. The Public Health Research Unit is supported by the Chief Scientist Office of the Scottish Home and Health Department and the Greater Glasgow Health Board. The opinions expressed in this paper are

not necessarily shared by the Scottish Home and Health Department.

1 McKeganey N, Barnard M, Leyland A, Coote I, Follet E. Female streetworking prostitution in Glasgow. BMf 1992;305:801-4.

McKeganey N, Barnard M. AIDS, drugs and sexual risk: lives in the balance. Buckingham: Open University Press, 1992.

Leonard TL, Freund M, Platt J. Behavior of clients of prostitutes. Am $\mathcal{J}$ Public Health 1989;79:903.

4 Day S, Ward H, Harris JRW. Prostitute women and public health. $B M Y$ 1988;297:1585.

(Accepted 9 fuly 1993)

\title{
Current practices in neonatal intensive care in the United Kingdom
}

\author{
C Day, R A Primhak
}

\section{Jessop Hospital for \\ Women, Sheffield \\ C Day, consultant \\ paediatrician \\ R A Primhak, consultant \\ paediatrician}

Correspondence to:

Dr C Day, Airedale Genera

Hospital, Steeton, Keighley,

West Yorkshire BD20 6TD

$B M F$ 1993;307:362
We set out to discover if there were any consistencies in clinical practices among United Kingdom nurseries with facilities for neonatal intensive care.

\section{Present survey and results}

A questionnaire was sent to a named consultant within each unit with neonatal intensive care cots listed in the directory of intensive care units. Details were sought regarding agreed policies for the following: birth weight or gestational age cut off below which intensive care was not offered; routine intubation and ventilation of very low birthweight babies; prophylactic drugs given to very low birthweight babies; use of sedation, paralysis, and antibiotics during ventilation; and whether a baby with stage 3 hypoxic-ischaemic encephalopathy would receive mechanical ventilation for respiratory failure.

Of the 140 units circulated, $106(76 \%)$ replied. Thirty seven $(35 \%)$ of the responding units did not offer intensive care below a certain birth weight or gestation. Among the 32 units that specified a gestational age the mode was 24 weeks (range 20-26). A birth weight cut off was specified by 17 units and generally this was $500 \mathrm{~g}$ (range 500-650).

Fifty two (49\%) units electively intubated babies below a specified gestational age. The modal gestational age cut off for elective intubation was 30 weeks (range 26-34). Once the infant was resuscitated, $51(48 \%)$ units continued ventilation in babies below a certain size until blood gas criteria justified withdrawal. The cut off point for this form of elective ventilation was based on gestation in all but two units (mode 28 weeks, range 26-34), but many specified birth weight as well (mode $1000 \mathrm{~g}$, range 750-1250).

Opinion was evenly divided on the management of

Frequency of routine practices in 106 neonatal units in the United Kingdom

\begin{tabular}{lc}
\hline & $\begin{array}{c}\text { No }(\%) \\
\text { of practices }\end{array}$ \\
\hline Ethamsylate in very low birthweight babies & $28(26)$ \\
Vitamin E in very low birthweight babies & $21(20)$ \\
Volume expanders in very low birthweight babies & $10(9)$ \\
Sedation of all ventilated babies & $35(33)$ \\
Antibiotics in all ventilated babies & $72(68)$ \\
\hline
\end{tabular}

stage 3 hypoxic-ischaemic encephalopathy. Thirty one $(29 \%)$ units would never ventilate a baby with this condition, $34(32 \%)$ would routinely ventilate such a baby in respiratory failure, and 37 (35\%) had no clear practice. The numbers of units with other routine practices are shown in the table.

When the units were divided into "large" (more than four intensive care cots) and "small" there was no significant difference in any mangement practice between them.

\section{Comment}

We have shown wide variations in clinical practice in neonatal intensive care in the United Kingdom, unrelated to the size of the unit. When two groups of clinicians differ in their use of an invasive treatment either one group is doing something unnecessary and potentially harmful or the other group is failing to give optimal care.

In a Danish questionnaire based study ${ }^{1}$ one third of units would not routinely resuscitate an infant delivered at 26 weeks. In the United Kingdom seven yeas later almost all units would do so, but over one third of units still operated some cut off, with considerable variation between units. About half the units surveyed electively intubated and ventilated small infants, despite little published evidence on the subject. A retrospective study using historical controls suggested that more aggressive resuscitation policies were associated with a reduction in the mortality from hyaline membrane disease. ${ }^{2}$ However, this practice has a potential morbidity, and when it is combined with elective ventilation for a longer period it may commit the baby to a cascade of intensive care procedures.

Neonatal intensive care has a long history of jumping on the wrong bandwagons, ${ }^{3}$ and many current practices have been introduced without objective evaluation. Collaborative randomised trials may resolve some issues, but it is not always possible to perform a randomised double blind controlled trial of every new management technique. If standardised outcome data were routinely collected the introduction of these new practices could at least be monitored by comparing outcomes in units which follow different management practices. Anecdote and intuition are no longer adequate guides to management in neonatal intensive care units.

\footnotetext{
Greisen $G$. Choice of treatment in very premature deliveries. A nationwide questionnaire. Ugeskr Laeger 1989;151:1612-4.

2 Robson E, Hey EN. Resuscitation of preterm babies at birth reduces the risk of hyaline membrane disease. Arch Dis Child 1982;57:184-6.

Silverman WA. Retrolental fibroplasia-a modern parable. New York: Grune and Stratton, 1980:69-89.

(Accepted 28 May 1993)
} 